\title{
Study on mechanism of spontaneous imbibition and pressurized imbibition in shale oil reservoirs
}

\author{
Lanlan $\mathrm{Yao}^{1,2} \cdot$ Zhengming Yang ${ }^{1,2} \cdot \mathrm{Haibo}^{2} \cdot \mathrm{Bo} \mathrm{Cai}^{3} \cdot$ Chunming $\mathrm{He}^{3} \cdot$ Debin $\mathrm{Xia}^{1,2}$ (1)
}

Received: 13 October 2020 / Accepted: 21 November 2020 / Published online: 7 December 2020

(c) The Author(s) 2020

\begin{abstract}
Imbibition is one of the important methods of oil recovery in shale oil reservoirs. At present, more in-depth studies have been carried out on the fracture system and matrix system, and there are few studies on the effect of energy enhancement on imbibition in shale oil reservoirs. Therefore, based on the study of pressurized imbibition and spontaneous imbibition of shale oil reservoirs in Qianjiang Sag, Jianghan Basin, nuclear magnetic resonance technology was used to quantitatively characterize the production degree of shale and pore recovery contribution under different imbibition modes, and analyze the imbibition mechanism of shale oil reservoirs under the condition of energy enhancement. The experimental results showed that with the increase in shale permeability, the recovery ratio of pressurized imbibition also increased. The rate of pressurized imbibition was higher than spontaneous imbibition, and pressurized imbibition can increase the recovery ratio of fractured shale. Spontaneous imbibition can improve the ultimate recovery ratio of matrix shale. Pressurized imbibition can increase the recovery contribution of macroporous and mesoporous.
\end{abstract}

Keywords Shale oil $\cdot$ Nuclear magnetic resonance $\cdot$ Spontaneous imbibition $\cdot$ Pressurized imbibition

\section{Introduction}

The inter-salt shale oil reservoirs in the Jianghan Basin are thin in thickness, with well-developed upper and lower salt layers, complicated reservoir lithology, high soluble salt content, poor technical effects of conventional measures, and short stable production periods, affecting the effective production of shale reservoirs. Volume fracturing and water injection huff and puff are the ways to effectively supplement formation energy. After volume reformation of shale oil reservoirs, a complex fracture network system is formed in a large area near the wellbore, the oil-water contact area is greatly increased, and the imbibition is sharp. Strengthening, which provides favorable conditions

Debin Xia

xiadebin16@mails.ucas.edu.cn

1 College of Engineering Science, University of Chinese Academy of Sciences, Beijing 101400, China

2 Institute of Percolation and Fluid Mechanics, China Petroleum Exploration and Development Research Institute, Langfang 065007, China

3 Fracture Acidification Center of China Petroleum Exploration and Development Research Institute, Langfang 065007, China for shale oil to improve recovery and profitable development. In recent years, imbibition oil production has been highly valued by oilfield development technicians due to its simple injection technology and lower operating costs and better oilincreasing effects. A large number of research results have been reported (Li et al. 2017, 2019; Zhou et al. 2017; Wang et al. 2018; Wei et al. 2013; Peng et al. 2010). Wu et al. (2019) established a new development model based on volume fracturing and imbibition oil recovery based on the principle that the effect of imbibition oil recovery after volume reformation of ultra-low permeability reservoirs increased significantly. Yang et al. (2020) established the evaluation method of salt dissolution in inter-salt shale oil-bearing cores using salt dissolution experiments, imbibition experiments and high temperature and high pressure nuclear magnetic resonance tests, and analyzed the influence of salt dissolution on spontaneous imbibition and permeability. Chen et al. (2017) took Daqing Fuyu reservoir fracture network fracturing fracture morphology and fluid as the research simulation object, carried out physical simulation experiment and mechanism analysis on the simulation model. It was found that with the increase in main fracture length and branch fracture number of fracture network, the imbibition area increased, the oil-water interpermeability enhanced, and the imbibition and recovery ratio increased. The 
combination of imbibition liquid and energizing agent also increased the recovery ratio of huff-puff imbibition. Zhu et al. (2002) studied the effects of different factors on imbibition in low permeability fractured sandstone reservoirs by using conventional laboratory imbibition experiments and nuclear magnetic resonance technology. By using low-field nuclear magnetic resonance (NMR), Meng et al. (2015) studied the distribution characteristics of fracturing fluid during spontaneous imbibition of shale. Chen et al. (1998) used nuclear magnetic resonance imaging and multiple relaxation separation technology to study the change law of the relaxation spectrum of fluid saturation distribution and the microscopic mechanism of imbibition in the process of imbibition of hydrophilic cores. Wei et al. (2016) used nuclear magnetic resonance technology to study the changes of oil and water distribution in the process of imbibiton of tight sandstone, and also analyzed the influence of microscopic pores on imbibition. Gu et al. (2017) further revealed the microscopic influence mechanism of tight reservoir permeability on imbibition efficiency through nuclear magnetic resonance technology and CT scan analysis. Jiang et al. (2012) established a new method for quantitative study of the imbibition efficiency of volcanic rocks by comprehensive application of nuclear magnetic resonance centrifugation technique in petrophysical simulation experiment. Through laboratory experiments, Mannon and Chilingarian (1973) simulated fractured matrix reservoirs and revealed the relationship between water injection rate and self-imbibition rate. It was found that under linear countercurrent conditions, the increase in water injection rate led to the increase in self-imbibition rate and the ultimate recovery ratio. Zuwa and Omoregle (1988) used mercury injection method and semi-permeable baffle method to determine the pore limits of the injected medium to displace crude oil. For the development of shale reservoir, it is very difficult to inject because of the extremely low permeability of reservoir and the start-up pressure gradient when water injection is used to replenish energy (Ghanizadeh et al. 2015; Saboorian-Jooybari and Pourafshary 2015). Zhang et al. (2019) effectively supplemented formation energy through the transformation mode of "horizontal well and volume fracturing," combined with oil production by waterflood swallowingspitting, which slowed down reservoir decline and enhanced the tight oil development effect. Hong et al. (2018) believed that the difference in permeability was the key to the energy supplementing method of separation and that the throat radius could be used as the sorting parameter of energy supplementing in tight reservoirs. Zhuang et al. (2014) found that nitrogen displacement can reduce the viscosity of crude oil and supplement the formation energy through volume expansion. Taking the inter-salt shale oil reservoir in Jianghan Basin as an example, based on laboratory physical simulation experiment and nuclear magnetic resonance technology, the study of shale pressurized imbibition and spontaneous imbibition was carried out. The contribution of different levels of pore throats to the imbibition efficiency was quantitatively characterized, and the influence of supplementary energy on the imbibition effect of shale oil reservoir was explored, so as to provide theoretical basis for the effective development of shale oil hydraulic fracturing by water injection huff and puff in Jianghan area.

\section{Geological background}

Jianghan Basin is located in central China, with a total area of about $36,000 \mathrm{~km}^{2}$. The northern part of the basin is the Qinling to Dabie orogenic belt. The south side of the basin is the Jiangnan to Xuefeng uplift. To the west of the basin is the Huangling anticline. The basements of the basin are mesozoic and paleozoic marine carbonate rocks, clastic rocks and continental coal-bearing clastic rocks. It has experienced the Yanshan movement and the Himalayan movement successively in geological time. Finally, an inland faulted salt lake basin was formed. Jianghan Basin interhalite shale oil is a typical type of shale oil in China. Qianjiang Sag is located in the central part of Jianghan Basin, covering an area of about $2500 \mathrm{~km}^{2}$. It is the most important salt-forming center in Jianghan Basin, and also a large hydrocarbon rich sag in this region (Wang et al. 2004; Bo et al. 2014; Wu et al. 2013). Compared with other depressions in the basin, Qianjiang sag has the deepest basement and the fastest subsidence rate. At the same time, Qianjiang sag is also a large hydrocarbonrich sag in the region. The thickness of the salt series strata reached $6000 \mathrm{~m}$. In plane, from north-west to south-east, there are delta facies, brackish lake facies and salt lake facies in sequence (Sun et al. 2020). The overlying and underlying strata of the shale oil reservoir in Qianjiang Sag are two sets of salt rocks, the lithology of which is mainly calcium mirabilite, dolomite, argillaceous dolomite and dolomite mudstone. In the drilling and exploration of shale oil in this area, one hundred and twenty-eight wells have shown oil and gas in the wellheads. Currently, a pilot development zone has been established, and fourteen wells have been put into production in the early stage, with the cumulative oil production of $4.2 \times 10^{4} \mathrm{t}$. One of the main characteristics of inter-salt shale oil storage is the high content of soluble salts $\left(\mathrm{Na}_{2} \mathrm{SO}_{4} \cdot \mathrm{CaSO}_{4}\right)$. With the progress of water injection development, salt dissolution occurs.

\section{Methodology}

Nuclear magnetic resonance (NMR) is a common test and analysis method for reservoir description and evaluation based on the observation of hydrogen nuclear signals in rock pores, the direct measurement of pore fluid properties, the acquisition of reservoir physical-property related parameters, and the calculation of dynamic fluid parameters. In the field of shale oil reservoirs, the measurement error of many 
common testing methods has become larger, thus misleading the interpretation of shale oil reservoirs. Nuclear magnetic resonance (NMR) technique can be used as an approximate nondestructive technique to measure the pore structure of shale oil reservoirs (Ju et al. 2019).

\section{Experiment}

Experimental equipment included intermediate vessel, precision pressure gauge, manual pump, beaker rubber rib (fixed plastic film) and plastic film mesh bag (to hold broken cores). The experimental equipment diagram is shown in Fig. 1. Figure 1a was the diagram of spontaneous imbibition experimental device. Figure $1 \mathrm{~b}$ was the diagram of pressurized imbibition experimental device. The experimental cores were obtained from the inter-salt shale oil cores in Qianjiang Sag, Jianghan Basin, with a porosity of 3.6-15.6\% and a permeability of $0.18-20.70 \mathrm{mD}$. Kerosene was used for the simulated oil, and 30,0000 ppm of simulated formation water was used for the experimental water (To counteract salt solubility). The experimental characteristics of imbibition method were quantitatively characterized by nuclear magnetic resonance (NMR), and the imbibition effects of saturated oil under pressurized and spontaneous imbibition were analyzed by combining NMR technology with laboratory physical simulation experiment. A Recore- 04 core NMR analyzer developed by The Institute of Percolation of Chinese Academy of Sciences was used as the main instrument for NMR experiments in this study. The main

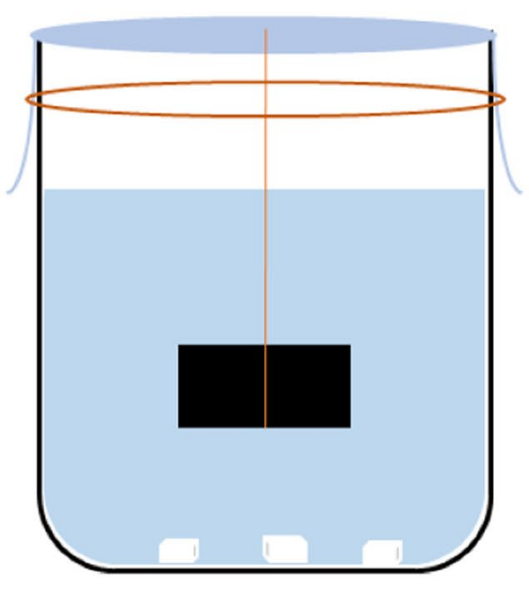

(a)

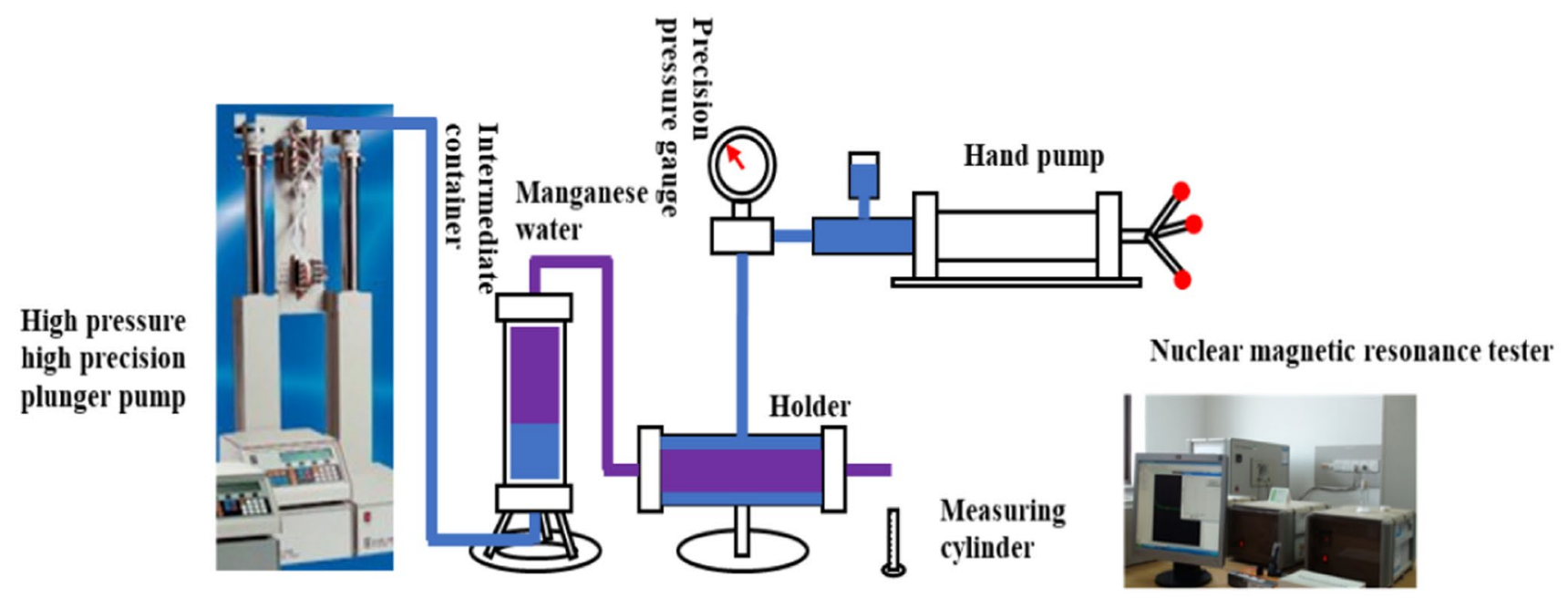

(b)

Fig.1 Experimental setup diagram 
test parameters were as follows: the echo interval time was three hundred microns, then the number of echoes was one thousand twenty-four, and the number of scans was sixtyfour, and the waiting time was three thousand milliseconds, finally the gain was fifty. The above data can be used as experimental parameters for all NMR $\mathrm{T}_{2}$ measurements. The influence of temperature on NMR results was reduced by measuring the standard sample before NMR test. The specific experimental steps were as follow. First, the five shale cores after oil washing were dried and vacuolized, then pressurized and saturated with kerosene, and finally fully saturated with kerosene. After completion, nuclear magnetic resonance test was performed. Then shale cores no. 1 , no. 2 , and no. 4 were placed in intermediate vessel with $30,0000 \mathrm{ppm}$ of manganese water (manganese water can cancel the water signal and show only the oil signal). Pressurized imbibition was performed under 16 MPa pressure, and nuclear magnetic resonance tests were performed at different time points until the map was almost unchanged. In addition, the no. 3 shale and no. 5 shale were put into 30,0000 ppm manganese water to absorb spontaneously, and NMR tests were conducted at different time points until the NMR atlas was almost unchanged. Finally NMR $\mathrm{T}_{2}$ map of different time nodes was drawn to analyze the imbibition results.

According to the relaxation time, the pores of Jianghan shale oil cores were divided into three types: macropores $\left(T_{2}>100 \mathrm{~ms}\right)$, mesopores (10 $\left.\mathrm{ms}<T_{2}<100 \mathrm{~ms}\right)$, and small pores $\left(T_{2}<10 \mathrm{~ms}\right)$.

\section{Experimental results and discussion}

\section{Pressurized imbibition}

Figures 2 and 3 are the NMR results of pressurized imbibition and spontaneous imbibition of shale, respectively. The study showed that the contribution of recovery ratio in different shale pores was different. Fig. 2 showed that the imbibition strength of no. 2 shale was less than that of no. 1 and no. 4 shale, indicating that the pressurized imbibition strength of matrix shale was less than that of fractured shale. With the increase in permeability, the effect of pressurized imbibition was also enhanced. As the time of pressurized imbibition increased, the peak position of shale began to shift to the right, indicating that the oil in small pores was gradually
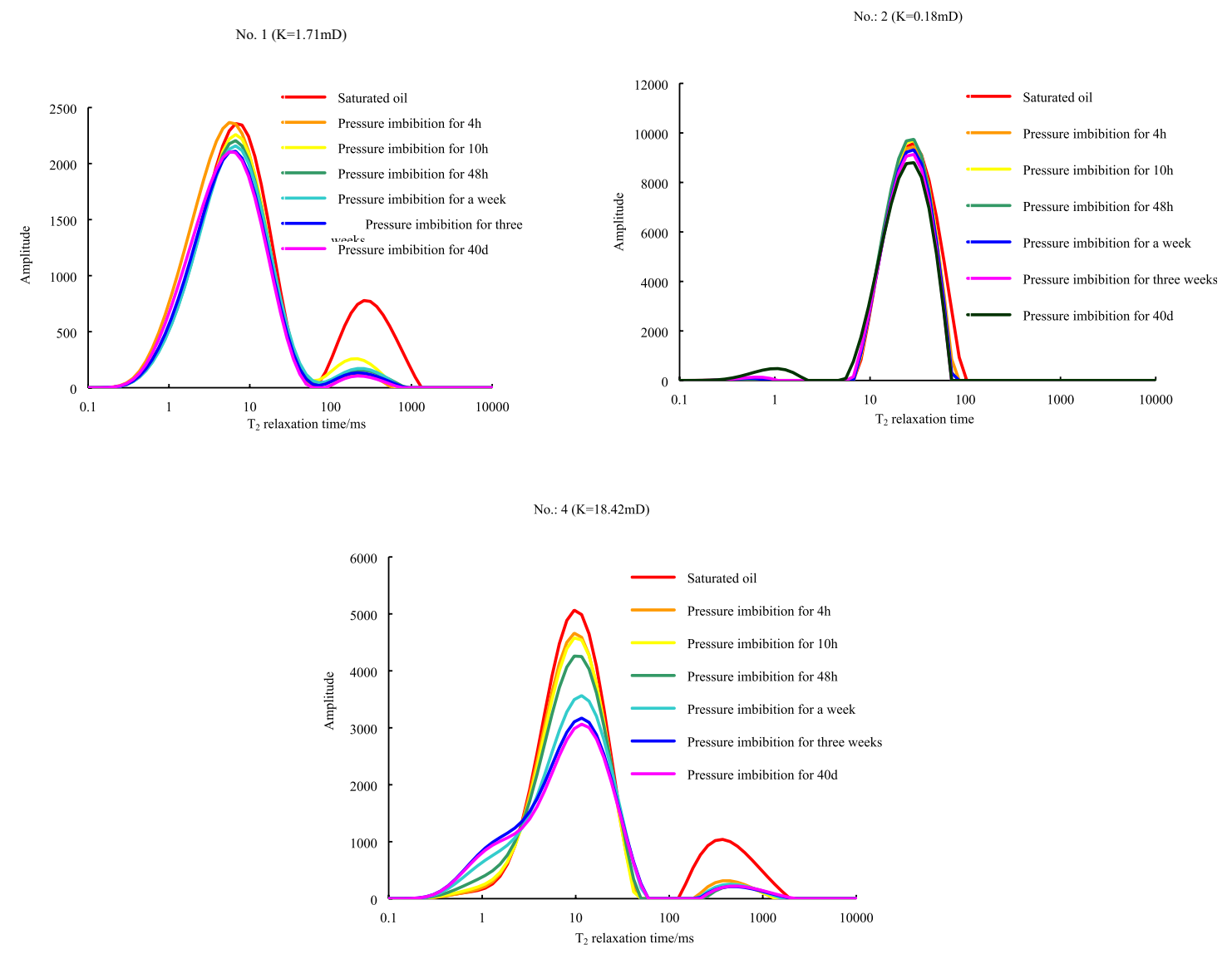

Fig.2 NMR spectrum of shale pressurized imbibition 

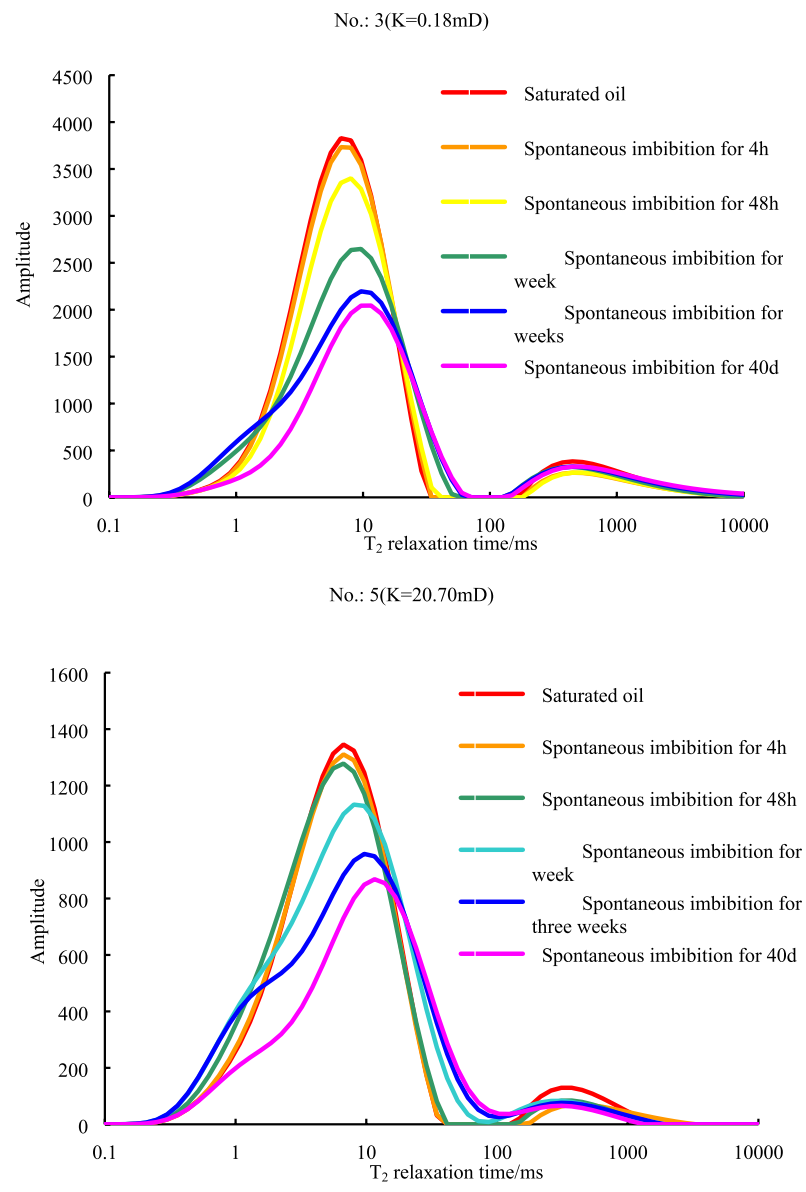

Fig.3 NMR spectrum of shale spontaneous imbibition absorbed into larger pores. In the early stage of pressurized imbibition, the decrease in amplitude of macropore signal was more obvious, indicating that under the action of pressure, manganese water preferentially entered into macropore for imbibition (Table 1). The signal volume on the leftmost side of no. 2 and no. 4 shale had increased after pressurized imbibition for a period of time, which may be due to the fact that oil entered smaller pores under pressure during the process of imbibition. It can be seen from Table 2 that the recovery ratio of no. $1(1.71 \mathrm{mD})$ shale was dominated by large pores, followed by mesopores, and the contribution of small pores was small. And the final recovery factor was $24.83 \%$. The recovery ratio contribution of no. $2(0.18 \mathrm{mD})$ shale was mainly mesopores, followed by large pores, and finally small pores. The final recovery ratio was $5.90 \%$. No. $4(18.42 \mathrm{mD})$ shale had the largest recovery ratio through macroporous pores, followed by small pores, and finally mesoporous pores, with a final recovery ratio of $32.23 \%$. It can be seen that as the permeability increased, the final recovery ratio also increased. Compared with matrix shale, fractured shale had a stronger pressure imbibition effect and a higher recovery ratio.

\section{Spontaneous imbibition}

As can be seen from Fig. 3, the peak states of matrix-type shale and fractured shale before and after spontaneous imbibition were both bimodal. The imbibition strength of no. 3 shale was greater than that of no. 5 shale, indicating
Table 1 Parameters of shale porosity and permeability

\begin{tabular}{lllllll}
\hline $\begin{array}{l}\text { Serial } \\
\text { num- } \\
\text { ber }\end{array}$ & Well depth/m & Lithology & Length/cm & Diameter/cm & Porosity/\% & Permeability/mD \\
\hline 1 & 3124.14 & Dolomitic mudstone & 4.97 & 2.54 & 15.6 & 1.71 \\
2 & 3126.89 & Dolomite & 4.10 & 2.50 & 4.3 & 0.18 \\
3 & 3745.84 & Calcareous clay & 4.04 & 2.55 & 3.6 & 0.18 \\
4 & 3393.35 & Argillaceous dolomite & 4.29 & 2.46 & 10.0 & 18.42 \\
5 & 3598.91 & Argillaceous dolomite & 3.32 & 2.55 & 4.4 & 20.70 \\
\hline
\end{tabular}

Table 2 Recovery ratio and pore contributions of shale under different imbibition methods

\begin{tabular}{|c|c|c|c|c|c|c|}
\hline \multirow[t]{2}{*}{ Serial number } & \multirow[t]{2}{*}{ Permeability/mD } & \multicolumn{3}{|c|}{ Recovery ratio of different pore $1 \%$} & \multirow{2}{*}{$\begin{array}{l}\text { Ultimate recovery } \\
\text { ratio } / \%\end{array}$} & \multirow[t]{2}{*}{ The imbibition way } \\
\hline & & Small pores & Mesopores & Macropores & & \\
\hline 1 & 1.71 & 0.33 & 22.34 & 77.33 & 24.83 & Pressurized \\
\hline 2 & 0.18 & 2.54 & 87.36 & 10.10 & 5.90 & Pressurized \\
\hline 3 & 0.18 & 94.25 & 1.25 & 4.50 & 39.27 & Spontaneous \\
\hline 4 & 18.42 & 34.90 & 25.70 & 39.40 & 32.23 & Pressurized \\
\hline 5 & 20.70 & 58.07 & 5.00 & 36.90 & 30.32 & Spontaneous \\
\hline
\end{tabular}


that the spontaneous imbibition strength of matrix -type shale was greater than that of fractured shale. As the spontaneous imbibition time increased, the peak position gradually shifted to the right, indicating that oil was gradually imbibed from small pores to large pores. In the early stage of spontaneous imbibition, the magnitude of the decrease in the left peak was greater than that of the right peak, indicating that manganese water first entered the small pores in the early stage of spontaneous imbibition. From Fig. 3, it can be seen that the right flank of the left peak of the shale began to move to the right after a week of spontaneous imbibition, and the peak area increased. Therefore, it could be concluded that as the spontaneous imbibition time increased, the shale began to appear micro-cracks, and the shale microcracks could also be observed on the surface of the sample. It can be seen from Table 2 that the contribution of no. $3(0.18 \mathrm{mD})$ shale recovery was dominated by small pores, followed by macropores and finally mesopores. No. $5(20.70 \mathrm{mD})$ shale small pores recovery ratio contributed more than $50 \%$, followed by macropores, and mesopores recovery ratio was the least. It can be seen from Fig. $4 \mathrm{~b}$ that the contribution of mesoporous and macroporous pores recovery in spontaneous imbibition of fractured shale was higher than that of matrix shale, and whether it was matrix shale or fractured shale, the contribution of spontaneous imbibition recovery ratio was mainly small pores. As matrix shale had more small pores, spontaneous imbibition can promote the imbibition effect of matrix shale and improve its final recovery ratio.

\section{Comparative analysis of pressurized imbibition and spontaneous imbibition}

By comparing the imbibition results of no.2 $(0.18 \mathrm{mD})$ shale and no. $3(0.18 \mathrm{mD})$ shale, no.4 (18.42 mD) shale and no.5 $(20.70 \mathrm{mD})$ shale, it can be seen from Table 2 that spontaneous imbibition can promote the imbibition effect of matrix shale better than pressurized imbibition and improve the recovery ratio. Pressurized imbibition can promote the imbibition effect of fractured shale and improve the recovery. As can be seen from Fig. 4, compared with spontaneous imbibition, pressurized imbibition can also improve the recovery ratio of macropores and mesoporous pores in matrix shale and fractured shale. It can be seen from Fig. 5 that pressurized imbibition can improve the imbibition rate of fractured shale, while spontaneous imbibition can improve the imbibition rate of matrix shale. With the increase in shale permeability, the production degree of pressurized imbibition also increased. The recovery ratio of no. 3 and no. 5 shale increased significantly after the imbibition time reached $500 \mathrm{~h}$, indicating that the spontaneous imbibition needed a long enough time to improve the recovery ratio.

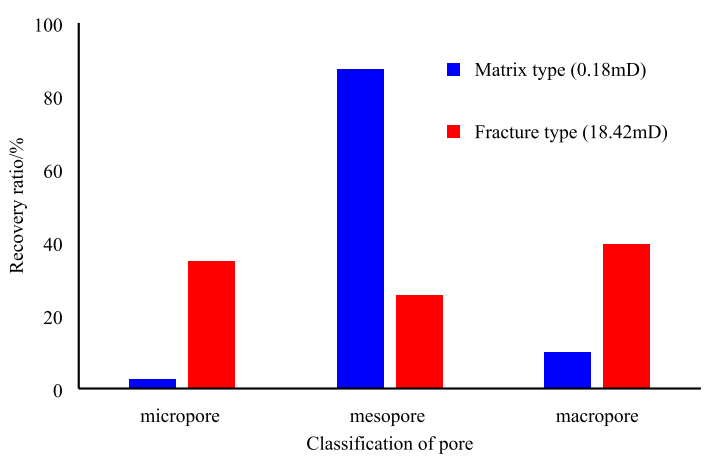

(a) Pressurized imbibition

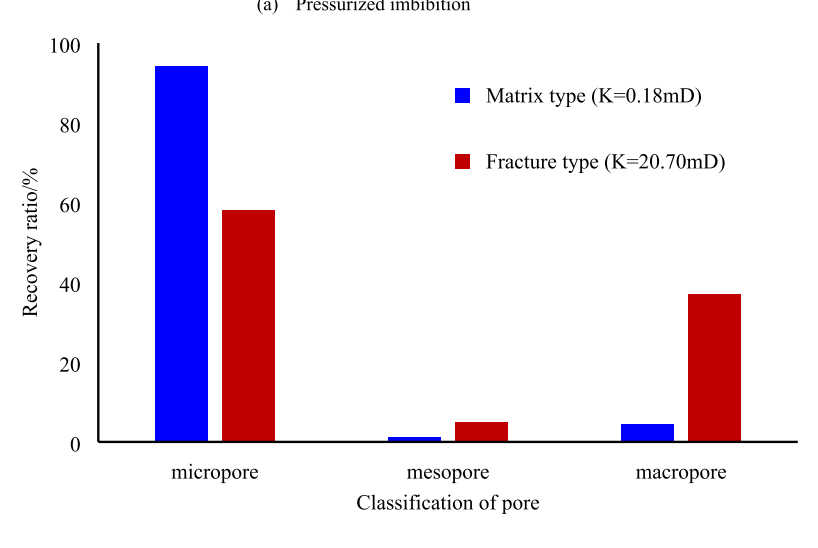

(b) Spontaneous imbibition

Fig.4 Contribution of recovery ratio of different pore throat by pressurized imbibition and spontaneous imbibition

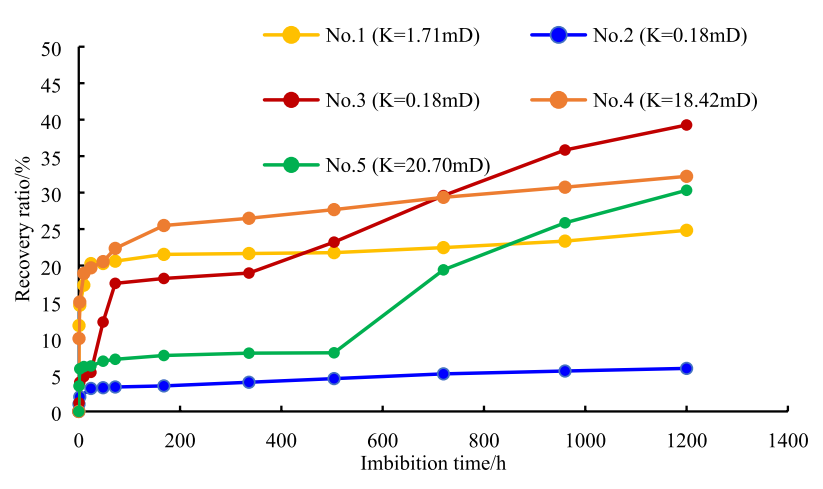

Fig.5 Imbibition recovery rate of shale over time

\section{Conclusion}

In this paper, considering the development of hydraulic fracturing of shale oil by water injection huff and puff, a study was carried out on shale oil under pressurized imbibition and spontaneous imbibition, and the imbibition and oil recovery effect of shale oil reservoir under the condition of energy increase was analyzed. The representative shale cores of Qianjiang sag group in Jianghan Basin 
was selected for the study on pressurized imbibition and spontaneous imbibition, and the following results were obtained.

1. With the increase in permeability, the ultimate recovery ratio of pressurized imbibition also increased. The ultimate recovery of fractured shale was greater than that of matrix shale. Therefore, the greater the degree of shale fragmentation during volume fracturing and water injection huff and puff, the better the effect of imbibition oil recovery.

2. During pressurized imbibition, the pore contribution of fractured shale recovery ratio was mainly mesopores and macropores, and matrix shale was mainly mesopores. During spontaneous imbibition of matrix shale and fractured shale, the pore contribution of recovery ratio was dominated by small pores. During spontaneous imbibition of fractured shale, the recovery ratio of mesoporous and macroporous pores was greater than that of matrix shale.

3. Comparing the two imbibition methods, spontaneous imbibition can improve the ultimate recovery of matrix shale, and pressurized imbibition can improve the ultimate recovery of fractured shale.

Funding This work was supported by Major National Oil and Gas Project (2017ZX05013-001, 2017ZX05049-005), Major Basic Science and Technology Project of China National Petroleum Corporation (2018B-4907).

Data availability The data used to support the findings of this study are available from the corresponding author upon request.

\section{Compliance with ethical standards}

Conflict of interest The authors declared that they have no conflicts of interest in this work.

Open Access This article is licensed under a Creative Commons Attribution 4.0 International License, which permits use, sharing, adaptation, distribution and reproduction in any medium or format, as long as you give appropriate credit to the original author(s) and the source, provide a link to the Creative Commons licence, and indicate if changes were made. The images or other third party material in this article are included in the article's Creative Commons licence, unless indicated otherwise in a credit line to the material. If material is not included in the article's Creative Commons licence and your intended use is not permitted by statutory regulation or exceeds the permitted use, you will need to obtain permission directly from the copyright holder. To view a copy of this licence, visit http://creativecommons.org/licenses/by/4.0/.

\section{References}

Bo JX, Shi WZ, He Y (2014) Sequence control factors and sequence model of saltlake in the lower fourth subduction section in qianjiang depression. China Pet Explor 19(1):22-30

Chen Y, Han DW, Lu XG et al (2017) Experiment on the effect of fracture morphology on permeability and oil recovery in low permeability reservoir. Pet Geol Dev Daqing 36(4):123-127

Chen Q, Zhou HT (1998) Experimental research on nuclear magnetic resonance (NMR) imaging in water flood developed heterogeneous reservoirs. OGRT 5(1):36-42

Ghanizadeh A, Clarkson CR, Aquino S et al (2015) Petrophysical and geomechanical characteristics of Canadian tight oil and liquid-rich gas reservoirs: I Pore network and permeability characterization. Fuel 153(1):664-681

Gu XY, Pu CS, Huang H et al (2017) Micro-scopic influence mechanism of permeability on seepage production in tight sandstone reservoir. Pet Explor Dev 44(5):1-7

Hong YF (2018) Separation and boundary of replenishing-energy methods in tight reservoirs Xinjiang. Pet Geol 39(3):340-344

Jiang WD, Yan J, Yang ZM (2012) A newmethod of studying dynamic gas seepage efficiency of volcanic gas reservoirs. J China Univ Pet (Edition Nat Sci) 36(1):101-105

Ju MS, Wang XY, Yu WS et al (2019) Static permeability and absorption law of tight reservoir based on nuclear magnetic resonance technology. Xinjiang Pet Geol 40(3):334-339

Li S, Ding YH, Yang YM et al (2017) Pressure permeability and absorption experiment and multi-scale simulation of tight core zone. J Pet Nat Gas 39(2):66-74

Li CL, Mao WY, Wu TX et al (2019) Study on the mechanism of oil permeability and absorption flooding. Xinjiang Pet Geol 40(6):687-694

Mannon RW, Chilingarian GV (1973) Experiments on effect of waterinjection rate on imbibition rate in fractured reservoirs. Energy Sources 1(1):95-116

Meng MM, Ge HK, Ji WM et al (2015) NMR study on shale spontaneous imbibition. Spec Oil Gas Reserv 22(5):137-140

Omoregle ZS (1988) Factors affecting the equivalency of different capillary pressure measurement techniq. Spe Form Evaluat 3(1):146-155

Peng LQ, He SL, Guo SP et al (2010) The effect of injection velocity on permeability of sandstone Xinjiang. Pet Geol 31(4):399-401

Saboorian-Jooybari H, Pourafshary P (2015) significance of non-darcy flow effect in fractured tight reservoirs. J Nat Gas Eng 24:132-143

Sun ZL, Wang FR, Han YJ et al (2020) Multi-scale characterization of the occurrence space of inter-salt movable shale oil in the Qianjiang Formation, Qianjiang Sag, Jianghan Basin. Pet Experim Geol 4:586-595

Wang XZ, Peng XL, Zhang SJ et al (2018) Characteristics of oil distributions in forced and spontaneous imbibition of tight oil reservoir. Fuel 224:280-288

Wang GL, Zhang YS, Yang YQ et al (2004) Evaluation of non-sandstone reservoirs in the Paleogene Qianjiang Formation in Qianjiang Sag Jianghan Basin. Pet Exp Geol 26(5):462-468

Wei HF, Fan ZY, Yuan XC (2013) Research progress in tight reservoir development technology. Pet Geol Recovery Effic 20(2):62-66

Wei Q, Li ZP, Bai RT et al (2016) Experimental study on the influence of microscopic pore structure on the infiltration of tight sandstones. Oil Drill Technol 44(5):109-116

Wu ZB, Li L, Yan YQ (2019) New development pattern of network fracturing and imbibition oil recovery for super-low permeability oil reservoirs. Fault-Block Oil Gas Field 26(4):491-494

Wu SQ, Tang XS, Du XJ et al (2013) Geological characteristics of continental shale oil in Qianjiang Sag Jianghan Basin. J Donghua Univ Technol (Nat Sci) 36(3):282-286 
Yang ZM, Li RS, Li HB et al (2020) Experimental evaluation of salt - solubility core of interhalite shale oil reservoir. Pet Explor Dev 47(4):750-755

Zhang CP, Ju YJ, Wang PP et al (2019) Development mode and energy supplement of horizontal tight oil wells in New Anbian Oilfield. Petrochem Appl 38(1):33-37

Zhou WF, Wang X, Lu XG et al (2017) Effects of the dynamic imbibition recovery and its influencing factors for the tight oil reservoirs. Pet Geol Oilfield Dev Daqing 36(3):148-155

Zhu WY, Ju Y, Zhao M et al (2002) Spontaneous imbibition mechanism of flow through porous media and water flooding in low permeability fractured sandstone reservoir. Acta Petrolei Sinica 23(6):56-59

Zhuang YT, Liu PC, Yang M (2014) Experiment study of CO2 and N2 flooding in low permeability field. Technol Eng 32:188-191

Publisher's Note Springer Nature remains neutral with regard to jurisdictional claims in published maps and institutional affiliations. 